\title{
Students' Perceptions of the Constructivist Instructional Methods in a Teaching and Learning Course
}

\author{
Siahaan, M. F. ${ }^{1}$ \\ ${ }^{1}$ Pelita Harapan University, Jl. M.H. Thamrin Boulevard, Lippo Village, Tangerang. \\ Corsesponding email: merifuji.siahaan@gmail.com
}

\begin{abstract}
Constructivism is defined as building one's own understanding. Constructivist instructional method requires that teacher should not be the one who informs but who facilitates the students learning. The purpose of this study is to obtain the students' perceptions on the implementation of constructivist instructional methods in Teaching and Learning course. A survey research methodology was used with first semester students who were taking teaching and learning course as the subjects of this study. Methods of collecting data were questionnaires with open ended questions, deep interview and documentation. A qualitative analysis technique was performed on data from the survey instrument and the interview to answer 4 research questions. A descriptive analysis technique was performed on data to answer 1 research question from the survey instrument and documents. The data analysis revealed that constructivism instructional methods were clearly experienced when they were required to answer a lot of probing questions, had discussion in the classroom, had Facebook online discussions with clear guidance to do so, created ted talks and debating.The study implies that the constructivist instructional methods experienced by the students in the class help them to better understand the constructivism theory and its implications.
\end{abstract}

Keywords: constructivism instructional methods; discussion; questions-answers; TED talks; debating

DOI: http://dx.doi.org/10.20961/ijpte.v1i2.15078

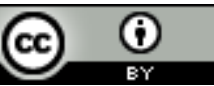

Except where otherwise noted, content on this site is licensed under a Creative Commons Attribution 4.0 International License. 


\section{CONSTRUCTIVIST INTRODUCTION METHODS}

Constructivist is grounded in cognitive learning theories that believes on the function of thinking and cognitive structures in learning (Lefrancois, 1999). The cognitive learning theory appeared as a response to the behavioristic which assumed human as biological or body that could response to his environment (Phillips, 2009). Given that assumption, learning is considered as acquiring new behavior that has nothing to do with mind and thinking. Contradicting with behavioristic, cognitive learning theory believes on the human's capacity to think and construct his own meaning. Piaget, Vygotsky, and Brunner are familiar names as those who developed cognitive learning theory (Lefrancois, 1999).

According to Piaget's theory, the learners use some important processes as they construct their knowledge, named; schemas, assimilation, accommodation, and equilibration (Phillips, 2009). Schema is knowledge organized in the learners' mind created as the learners construct an understanding of the world. The schema created by each person is differently structured from a simple to a complex one which according to Piaget depends on their biological development. For example; a baby has a simple schema that involves an action such as sucking, looking, and grasping. As he grows up, he might have a more complex schema that involving a strategy of identifying objects by their physical characteristics such as color, size or shape. As he becomes an adulthood, he might have constructed some complex schemas such as classifying objects by its function, its beauty, and its controversial issues (Santrock, 2009).

The schemas that one has created will be adapted as he gets new information which are called assimilation and accommodation. Assimilation occurs when the learners can deal with the new experiences and incorporates it with the existing schemas that will preserve equilibrium (Santrock, 2009). Equilibrium is a thinking process where the learners relate their existing schema with the new experience that result continuous change of schemas (Gredler, 2001). Accommodation occurs when there is a conflict between the new experience with the existing schemas which results disequilibrium and the learners will try to adjust the schemas to resolve the conflict and reach the equilibrium (Santrock, 2009).

As each child experiences those mental processes or called constructing knowledge, their schemas will be developed, a process of reorganize schemas occur and will get them to the new ways of understanding environment around them. Santrock described four stages of cognitive development that Piaget's theory proposed. Everyone go through those stages as a result of the constructing knowledge processes. Sensorimotor is the first stage which start from birth to 2 years of age. In this stage, infants develop schema to construct an understanding of the world by coordinating their sensory experiences such as seeing and hearing with their motor actions (such as reaching, touching). The second stage is preoperational stage which starts from about 2 to 7 years of age. This stage is called symbolic thinking where children develop their understanding of the world with words and images. Another stage of cognitive development is concrete operational stage from 7 to 11 years of age. The children construct their understanding of the environment by classifying objects by its size, color or 
shape. This is the stage where the children can think logically about concrete events. Formal operational stage is the last stage. This stage occurs to the 11 to 15 years of age through adulthood. Characteristic of this stage is an ability of thinking abstractly (Santrock, 2009).

Vygotsky proposed another cognitive theory grounded constructivist. One of principles that Vygotsky emphasized in his theory is the influence of culture on human's cognitive development. He concluded that cultural diversity in terms of symbols or tools used influenced mental growth. Having different symbols used in an individual's life events within a certain culture, the brain established new connection to that symbols that communicating ideas. Thus these symbols and objects are used to remind the individual of something (Gredler, 2001). This means external factor that is the tools contributes to human cognitive development which different from each culture. Vygotsky's ideas of cognitive development disagreed with behaviorism point of view that human behavior is determined by the stimuli given in the environment without any mental process (Eggen \& Kauchack, 2007).

The assumption that cultural contributed to an individual's mental growth implies not all of the children experienced the sequenced cognitive development stages as proposed by Piaget's theory. Vygotsky's theory viewed that learning leads to development which contradict with Piaget's theory that biological development leads to learning. This does mean that biological factor has nothing to do with the cognitive development as noted by Gredler (2001) Human cognitive development is influenced both by biological and cultural factors. The biological factor is responsible for simple mental functions such as simple perception and memory.

Another principal of Vygotsky's work is the zone of proximal development. This principal believes that everyone has three zones of learning; what is known, what is not known. The area between those two zones is skill that can only be mastered by a child with guidance from a knowledgeable person. This area of learning is called the zone of proximal development (Smith, 1998). This principal of the zone of proximal development reflects the importance of social interaction in learning (Santrock, 2009) as well as an identification of the student's readiness or potential development (Gredler, 2001). Echoing to the principals of Piaget \& Vygotsky's learning theories, constructivist approaches to teaching are characterized as follows:

1. Teaching and learning should stress relationship and strategies

This means learning as an active process of the learning in building relationship the information with what they already know. This character calls strategies that involve in perceiving, interpreting, organizing, analyzing, evaluating, storing and retrieving information (Lefrancois, 1999)

2. In terms of social nature of learning, the interactions between a knowledgably member of society and the child is significantly important in the high mental process thus learning activities should be interactive, relevant authentic and provide effective scaffolding such as questions and prompts (Santrock,2009) 
3. The views of the importance of social interaction to develops higher cognitive processes and that the culture determines the ways people perceive, analyze and interpret an event, the students would benefit in terms of hearing multiple perspective that would enrich each one's understanding (Gredler, 2001)

4. The interaction with the knowledge able others would benefit the child in terms of the child's ability to learn by observation and imitation. This call a role of modelling from the more knowledgeable others (Phillips, 2009)

5. Constructivist learning theory suggests that learners construct an understanding. They do not record knowledge in an attempt to make sense of those experiences. This means learning is not a process of transferring knowledge from the teacher to the students. Instead, required the teacher to play a role as a facilitator to connect content with the world (Eggen \& Kauchack, 2007)

Echoing to teaching approach that welcome multiple perspectives in interpretation as a higher cognitive process, Van Brummelan noted strongly that this can be one of the weakness of constructivist based learning that is its relativistic value. The relativistic values will drive the students to interpret truth based on their own interpretations as the result of their own interactions with their own experiences (Brummelan, 2009). This calls another role of a constructivist teacher that is not only as a facilitator but also to lead the students to the eternal truth.

\section{THE PROBLEM}

Teaching models and instructional strategies grounded on constructivist learning theories have been widely discussed by teachers. Moreover, 2013 Indonesian 'national curriculum requires that the teachers implement inquiry, discovery, scientific, project based learning approaches as written on government's rules 2016 number 22 about proses standard on curriculum 2013 (Government, 2016). Those teaching approaches are all grounded on constructivist learning theories. Also, there have been a lot of scholarship that have been discussing and generating constructivist instructional strategies.

John \& Clark discussed failure of Constructivist, Discovery, Problem-Based, Experiential, and Inquiry-Based Teaching because of the minimal guidance. They suggested that maximal guidance are effective for novice to intermediate students as implemented constructivist teaching approaches (Kirschner, Sweller \& Clark, 2006). Sanford Gold studied the pedagogical role of the teacher in a course named online education that used a constructivist instructional methodology. The findings revealed that the teachers exposed to the course changed their attitudes toward online instruction. They see online instruction is more participatory and as extension of their faculty work (Jonassen, 2006).

Biesta gave critiques to the use of the language "learning" that is based on the constructivist and social cultural theories of learning which believe that the students are not passive learners, instead, they actively construct the knowledge. Biesta argued that regardless its positive impacts, the use of the language of 
learning is affected by the rise of neoliberalism and marketization of education which are arguable in terms of three points. First, it is against a line of thinking. This describes the learners as the ones who already know what they want and the teachers and the education institutions as the providers whose role is to meet the students' need. Having that kind of role, the teachers are required to satisfy the learners' need who are considered as costumers. Second, the language "learning" makes it difficult to raise questions about the content and purpose of education. Viewing the students as the customers and the students as the providers, the purpose of education including what and how to teach are drawn to purpose of market which is characterized as attractive, easy and exciting. Third, marketing the purpose of education, it is hard to create democratic deliberation about the content and purpose of education and its role in society (Biesta, 2005).

Despite of lots of discussions and arguments among scholars and teachers about constructivist teaching approaches, it is seldom to hear the students' perspective on Constructivist based learning. How do students define constructivism based learning? What kinds of challenges the students experience when having constructivism based learning? What difficulties the students find when having constructivist based learning? It is the need to understand the student's perception of constructivist instructional methods that can provide a rich source of data to help teachers and lecturers approach their classes with constructivist instructional strategies.

\section{RESEARCH QUESTION}

This study investigated the idea of constructivism based learning from the student's perspective. The study was guided by the following questions:

1. How did students in this class define constructivism based learning?

2. Is there consensus among the students to whether constructivism based learning occurred in the class?

3. What specific examples of constructivism based learning do the students identify from the class?

4. What were challenges experienced by the students when having constructivism based learning?

5. What difficulty/ies did the student find when having constructivist based learning?

\section{METHODOLOGY}

The research questions in this study were answered using survey research methodology since this study was to obtain the students' perceptions of constructivist based learning. The data collected through the survey instrument were qualitative data. Interview students and documentation were other methods used to triangulate the data. 


\section{PARTICIPANT AND DATA COLLECTION PROTOCOL}

The participants in this study were students in one of the researcher's class. They were junior Chemistry education students. The course was a Teaching and learning course that presented learning theories underlying models of teaching and others teaching practices such as behaviorism, information processing, Piaget and Vygotsky's leaning theories, multicultural education. The diagnostic survey was distributed before the class to get information whether or not the student were familiar with the term constructivist based learning. The result showed that they never heard about each learning theories included in the course. The diagnostic instrument was also to obtain information about learning activities they experience during their previous study. The data informed that direct instruction was the most teaching model they experienced. Thus, it was assumed that the students were not familiar with constructivist based learning.

The survey instruments were distributed in the last session of the class. The lecturer told the students that she was interested in knowing how well the constructivist based learning was implemented in her class. Therefore, she was interested in getting an understanding of how her students perceived constructivist base learning in her class. The researcher distributed 25 survey instruments and a total of 21 students completed the survey.

\section{Questionnaire Design}

The survey asked the students to describe their understanding of the constructivist based learning, to indicate whether constructivist based learning had occurred in the class, to identify how constructivist based learning had occurred and identify the students' challenges as well as difficulty experiencing constructivist based learning. The questions were open ended questions.

\section{Analysis of the Data}

This study used qualitative and descriptive approaches to analyze data. Qualitative analysis technique was performed on data to answer research question 1, 3, 4 and 5 from the survey instrument and the interview by coding and developing categories. The survey instrument was treated as the primary data. Documents were used to support the survey data analysis. Descriptive analysis technique was performed on data to answer research question 2 on the survey instrument and documents.

\section{FINDINGS}

\section{RESEARCH QUESTION 1}

Research question 1 asked, "How did students in this class describe constructivist based learning?” To get this data, the survey instrument asked students to respond 
to this question, "Describe your understanding about constructivist based learning!” Although constructivist learning theory was one of topics discussed in this Teaching and Learning class, but all of the students were not familiar with this term and almost never experienced this type of learning during their school years. Thus, it was assumed that these descriptions of constructivist based learning reflect the students' personal interpretation. The findings from the survey were supported by the interview data which asked the three students to give more explanation on what they responded on the survey. All twenty-one students responded to this question. Their responses fall into six categories as follows:

1. Making connection

2. Engagement

3. Inquirer

4. Teacher's role

5. Student centered

6. Critical thinking

Data analysis presents a total of 33 definitions in the six categories. One definition which is Teacher's role was placed in two categories. The distribution of definitions within these categories is illustrated in figure 1.

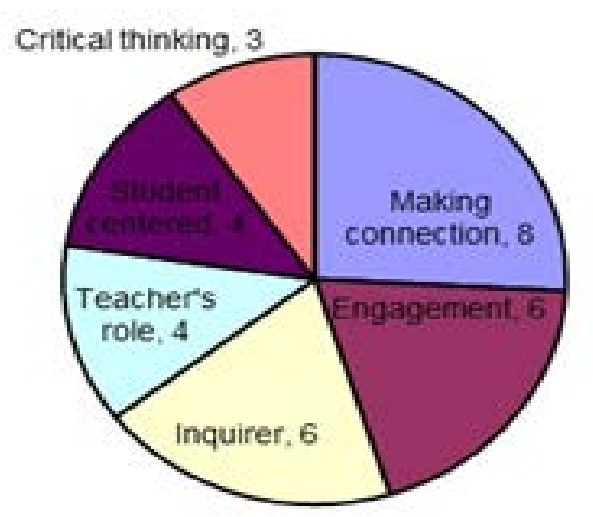

Fig. 1: Distribution of Definitions of Constructivism Based Learning

\section{Making Connection}

The largest group of definition $(n=9)$ refers to the category labeled making connection. Definition in this category described constructivist based learning in terms of relationship between previous and new learning that construct meaning. Four students described constructivist based learning as using the existing understanding and knowledge based on the previous learning to understand the new information. Other four students described as making connection with the real experiences in daily life. Three of those eight students described that using previous knowledge in learning new things makes learning easier. The descriptions of two students tended to convey an understanding of constructivist 
based learning in terms of the process of accommodation, adaptation and term of disequilibrium.

The result of interviewing three students emphasized constructivist based learning as relating their experiences with the new information to construct new understanding about the topics being learnt. A student said "What I understand about constructivist based learning is the learning that connects with what the students have understood with the new material. For Example, when we discussed about the relationship between Social Economic status with the learning. You used a lot of questions to recall our experiences about how the students from three different schools under our institution (with different social economic background) experienced learning”.

Another student tended to give a theoretical explanation. He used literally terms in constructivist theory such as disequilibrium, accommodation and adaptation. "Usually classroom is a place to give an understanding to the students but constructivist based learning is to construct the students' understanding. It occurred when the students could make connection between the prior knowledge with the new topic. Through what? Through disequilibrium, for example; I have knowledge and it does not incorporate, then I experience disequilibrium. Then I will accommodate and adapt the new knowledge. But learning can occur when the new information is in line with what I know that I need to develop deeper what I already know".

One student mentioned inquirer and a teacher's role as explaining constructivist based learning as that of integrating new knowledge into existing knowledge. She said "According to me constructivist based learning, the teacher in the classroom only gives trigger. She only gives stimulus. The ones who search the core of the material being learnt are the students themselves. Construct begins from her own experiences, stick it on the new experiences. Then check whether the definition developed is in line with what are written on the text book or the teacher's understanding. This is what it means inquirer. So, she develops an understanding not receiving the understanding. If she only receives it, it can be forgotten, but if it is constructed, the new understanding may not be the same literally as written on the book but the essence remains the same”.

\section{Engagement}

Constructivist based learning as engaging the students in learning was the focus of six students' definitions. Definitions in this category described constructivist based learning in terms of the students' active engagement in learning instead of to be the passive learner. One student expressed it as being engaged in thinking critically. Another definition described constructivist based learning as being engaged actively in understanding the material learnt. 


\section{Inquirer}

The six students in this category refer to constructivist based learning in terms of inquirer. Definitions in this grouping emphasize constructivist based learning as a process of inquiring by themselves. Three students viewed inquiry as the process of the students themselves develop relationship between previous experiences with the current learning. For example; "Constructivist based learning is where the students construct their own understanding and that understanding is inquired by the students themselves throughout making relationship to the previous real experiences". One students said "the process of finding out requires the students to think critically". The other two students focused the definition of inquiry as that of the teacher's role as a facilitator. "Constructivist based learning is the learning that get the students inquire and the teacher plays a role as a facilitator" "the students find a solution by their own inquiry and the teacher is still in control to guide the students".

\section{Teacher's Roles}

Four students 'definitions were placed in the category labeled teachers' role. These students described constructivist based learning in terms of the teachers' role in facilitating the students' learning. This definition was also categorized in the category labeled "student centered". Three students used these words, "The teacher plays a role as a facilitator". Two of those three students defined facilitators as the one who did not explain the material all the way to the students and the one whose responsibility is to develop the existing knowledge of the students not to transfer the knowledge all the way. One student said "the teacher controls by guiding the students learning”.

\section{Student Centered}

Some students referred constructivist based learning to the category labeled student centered. These four students described constructivist based learning in terms of the students' and the teachers' roles. Three students considered constructivist based learning to be the students' role in the learning process. For example; "Constructivist based learning implies a principal of student centered. In the classroom, the students are ready to learn by using their own previous learning". All of the students in this category referred to the teachers' role "Constructivist based learning is learning that centered to the students and the teachers are only as facilitators. The teachers develop the knowledge that the student already have”.

\section{Critical Thinking}

Three students fit in the category labeled critical thinking. They defined constructivist based learning in terms of thinking critically to be able to inquire. 
One student expressed "The students develop their own understanding and it required to think critically". Another student responded "constructivist based learning is learning where the students construct meaning through critical thinking and develop their own understanding. One student said "process that engaged the students to think critically"

\section{RESEARCH QUESTION 2}

Research question 2 asked, “Is there consensus among the students' as to whether constructivist based learning occurred in the class?” Data to answer this question were collected from the second question on the survey instrument. It asked "Did constructivist based learning occur in this class?" The students answered this question by writing "Yes" or "No". All the twenty-one students responded to this questions. All the students answered "Yes" constructivist based learning occurred in this class.

\section{RESEARCH QUESTION 3}

The third research question is "What specific examples of constructivist based learning do the students identify from the class?" Students were asked to answer open ended question on the survey instrument. The survey asked "What specific examples of constructivist based learning did you identify from the class?” The students' responses fit into 6 different categories as follows:

1. Lecturer's probing questions

2. Facebook on line discussion

3. Ted Talk

4. Debating

5. Discussion

6. Reading before class

Data analysis presents a total of 19 activities in the six categories. One activity which is lecturer's probing question was expressed broadly than other categories thus it was placed in two categories that is reading before class category. The distribution of the activities within these categories is illustrated in figure 2 . 


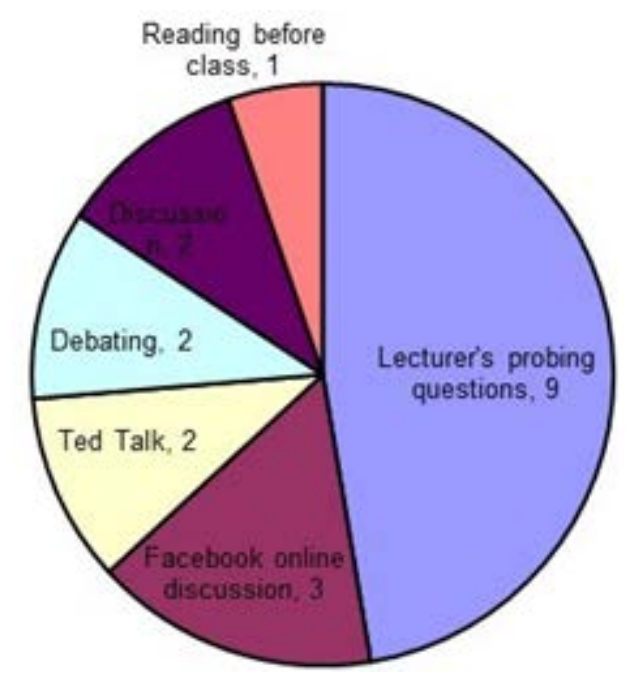

Fig. 2: Distribution of Examples of Constructivism Learning

\section{Lecture's Probling Questions}

Lecturer's probing question is the largest category of this second research question ( $n=9)$. Two students said "The class began with questions and the learning proses were discussing the questions". A student expressed "in learning the lecturer gave questions that triggered us to think critically". Two students wrote "The teacher stimulated the students in learning by raising questions that challenged the students' curiosity and develop the existing schema”. One said "the questions stimulated to participate in learning". "Another student wrote "the questions that led the students think and find answers". Two students said "guiding questions". The interviewed data gave further information about guiding questions which was also classified in the "reading before class" category.

The guiding questions file which as one of the documents showed guiding questions provided in each session as well as pages of text books the students were expected to read. The guiding questions served not only to guide the students' reading prior the class but also to emphasize the main points the students needed to understand in each session. They were reminded that they did not need to remember all information but the most important thing was to understand principals of each learning theories to be covered in this class and how those principals related to their own experiences (see appendix A for the guiding questions provided in the class).

\section{Facebook Online Discussion}

Three students responded that Facebook online discussion was an example of constructivist based learning in the class. Given an activity Facebook on line discussion, agreement upon the time and the length of being on line were discussed. An obedience upon the agreed time was also assessed. The students did this activity for three times within three random sessions selected by the lecturer. 
Two students wrote specific activity on Facebook on line discussion that was to write summary. The interview data gave further information about the way Facebook on line discussion constructed the students' understanding. The students explained that Facebook on line discussion included writing summary, listen to other's opinion and discussion. Writing summary required the student to express their own understanding using their own words. Also, the students were asked to read their group's member summaries. This way the students were enriched by multiple perspectives in the summaries. The students did not receive only from the teacher's perspective, which sometimes she felt the teacher's sentences are too heavy and her friends' explanation on summaries are simpler and easier to understand (see appendix B for Facebook on line discussion procedures).

\section{Ted Talk}

Ted Talk was also an example of constructivist based learning in this class $(n=2)$. The interview data viewed Ted talk in terms of knowledge-deepening activity. The students said "Ted talks and debating were activities as continuation of the questions being discussed in the classroom. We dig deeper the topics we had been discussing in the class. Unless we did that, we had known only the superficial things. These activities helped us to dig deeper and was still under your guidance”.

When being asked what, she meant about guidance. She answered "We asked questions, we asked a lot of questions to you. How was it? Was what I planned was correct? This was like we were working on finding out and asked your clarification. So, you were not the one who gave the answer but we searched. Then we would come to you again and asked questions about what we had been working on”.

The student was asked to tell the way Ted Talk facilitated her to construct meaning. She said "Even to create the title, we needed to construct. First we needed to understand our background of choosing that title. Then we needed to understand the material that has connection with the background. Then we created the title and the title should be interesting. Automatically our thoughts were ransacked. It was not shallow. Even it was only a simple idea, but we needed to dig deeper on that simple idea. So, I think it was very constructive”.

This student mentioned "background" and what she meant with "background" here was theoretically called schema. She should recall the schema in the process of making linkages between the schema and the new knowledge which was the principal of learning theories being learnt. The process of integrating the principals of learning theories that they just learnt (new knowledge) with their own experiences (old knowledge) was expressed in one of steps provided by the lecturer in designing the Ted talks (see appendix $C$ for the steps of designing Ted Talks). 


\section{Debating}

Debating was another category that two students responded as an example of constructivist based learning. The interview data viewed Ted talk in terms of knowledge-deepening activity. The students said "Ted talks and debating were activities as continuation of questions being discussed in the classroom. We dig deeper the topics we had been discussing in the class. Unless we did that, we had known only the superficial things. These activities helped us to dig deeper and was still under your guidance” The steps of doing the debating were basically the same. The difference were only technicalities. The debating was a group work and Ted talk was individual project. The debating was a project that each group should develop rational and supporting theories upon their agreement or disagreement on controversial issues the lecturer provided. The Ted talk worked on the other way around in terms of building their own agreement or disagreement on any experiences they wanted to use.

\section{Discussion}

Discussion is another method that three students viewed as constructivist based learning. The discussion included teacher and whole classroom discussion and small group discussion. One student responded "When we discussed about the relationship between Social Economic background and the learning. You brought up many questions and used Pelita Harapan School, Dian Harapan School and Lentara Harapan School as examples”. These three schools are under one school system but each has different social economic background. The result from interview supported the category "discussion" as an example of constructivist based learning that occurred in the class. The survey instrument showed that this student did not write anything about the discussion but when being interviewed, he mentioned about discussion as the example of constructivist based learning. He said "Usually the class began with discussion, discussed pages we read prior to the class. We read the same pages but the way each one of us digested were different. We shared our experiences related to the pages we read. Then the teacher gave clarification”. When being asked to give further explanation about the way constructing an understanding occurred in the "discussion", the student said "Discussion was in a group where each one commented on the questions given. Not only answering questions, but we were usually asked to develop definition, not from a book but based on our own understanding”.

\section{Reading before Class}

Only one student responded to "reading before class" as an example of constructivist based learning. This student was interviewed to give clarification about what he meant reading before class. He said "Before class, we read the material given in the dorm so when we were in the classroom, we had an understanding about it. So, in the classroom, was to develop what we had read. So, in the classroom, we were not spooned but developed what we had read prior 
to the class". When being asked to describe how construct an understanding throughout the activity "reading before class" occurred. He answered "Take an example behaviorism. Usually if it was to give an understanding, we just copied from the lecturer what it meant behaviorism. Behaviorism was a learning theory where bla bla bla but what was done in the Teaching and learning classroom, we were helped by reading the materials before class. Guiding questions were provided to lead us get the points of what was being read. For example; what it meant behaviorism. Then the lecturer led us out to recall our experiences of elementary school. She questioned if we did not do any homework, what had happened to us. We got pinched or our scores reduced...well that was behaviorism to get people behave by giving punishment and reinforcement. We have been experiencing those things, then a cool word "behaviorism" came up. But we got that idea until being related to our own experiences. What we experienced was implementations of behaviorism, then we made our own definition about behaviorism”.

The student was also asked what he understood about the guiding questions that construct meaning. He said "Guiding questions are questions leading us to think. Take the example I mentioned before about behaviorism. The question was not about the definition of behaviorism. Instead, how were your experiences when you did your homework and you got good scores or you did a mistake and got a punishment? What do you think the purpose of punishment at that time? Then we got an understanding that punishment and reward to get us behave. So, the intention of the guiding questions was to lead us thinking. Guiding questions did not require us to recall information like "what" question. Instead, asking what was your opinion? Why did you have that kind of opinion?”.

Interviewing with another student who did not respond about guiding question on survey, she explained "You often gave us questions. What did you know about this? We thought, thought. Then we talked and gave comments. After that you gave comments on our thoughts or you questioned us back. Then aha, this experience was related to this theory and other experiences were connected as well with this theory”.

\section{RESEARCH QUESTION 4}

Research question 4 asked "What were challenges experienced by the students when having constructivism based learning?” The result of analyzed survey instrument revealed three categories; think critically, making connection, and creating and answering questions.

\section{Think Critically}

Six students commended that think critically was what challenged them. These were their typical responses "My challenges are to think critically and aware of the connection between the learnt material with the real experiences". "Thing 
challenged me when I was expected to think in a discussion and to create logical questions as well as to answer my friends' questions". "I was challenged by being forced to always think critically". Another comment tended to be his participation on thinking as his challenge. "I was challenged to actively participate in thinking”.

\section{Making Connection}

Five students responded that making connection between their experiences with the current learning was their challenge "...a lot of to be related with experiences at school”, “.... and how I made connection between what I received with my daily experiences", "think critically and to be aware of the relationship between the material with the real experiences", “ ...need to think critically and remember experiences", "the ability to think critically and develop connection between the current learning with the previous experiences"

\section{Creating Questions and Answering Connections}

Creating and answering other's questions were parts of activities on Facebook online discussion. After writing on 200-250 words summaries on selected topic, they were asked to create each two questions with some criteria as follows:

1) The questions are critical and give challenging perspectives

2) The questions are not recalling questions about information we have been discussing (using questions such as what and who)

3) The questions are not merely asking whether a person experiences those as mentioned on the theories

4) The questions give new ideas or concepts that are not yet discussed in the class (this means you can use "what questions" that are not meant for recalling information)

5) The questions may ask an experience/s of your own or others or a context that are/ not informed by the theory or

6) The two questions created should reflected the first up to sixth criteria

Given those criteria, three students viewed that creating and answering other's questions were challenges for them. "For me thing that challenged was to think concrete answers and to create questions, "To create logical questions and answer friends' questions”, “To think and answer questions”.

\section{RESEARCH QUESTION 5}

Research question 5 asked, "What difficulty/ies did the student find when having constructivist based learning?" The students' responses on question number 5 on the instrument survey were data for this research question. Think critically was the only emerging category appeared. 


\section{Think Critically}

Four students viewed think critically as difficulty as they experienced constructivism based learning. Comments were "had no habit to think critically and my previous learning experiences since I was in elementary made me like to be a listener", "not sharp enough to analyze or dig deeper", "I was not able to think critically and fast" and "difficult in understanding abstract concept that I need teachers' explanation".

The interview of one of the students confirmed the reason think critically difficult in constructivist classroom. She said "Honestly, when you asked a lot of questions in the class, I thought but I was not able to talk. Why I could not talk? Because...well now I can talk ... a little bit aware. Why I could not talk and say my opinion or think deeper because of my previous education. I mean my previous schools always delivered material, always transferred material that getting me know but not experiencing. I knew as much as being delivered to me. If what was given as big as a ball so that big I was supposed to know. If I knew as big as the ball, then my grade would be good enough and I did not need to study more, no need to search for more. That kind of education I experienced until I was in senior high school. So not talking was kind of my habit”.

Another interview informed her difficulty in terms of sharping understanding. She explained: "Everybody had different opinions, different experiences that ended up with different understanding. So, for example, in the discussion, everybody was given an opportunity to give opinion toward questions given. Sometimes I was not able to get into others' opinions. It was like analyzing incorrectly. I was like considering others' opinion were indeed wrong. It was not open, wasn't it? Well needed to be open. Who knows his/her opinion was better but because I was not able to analyze the meaning of his/her opinions, that was why I was not open enough”.

One student commented that reading before class was his challenge as well as his difficulty in the constructivist classroom. "Honestly, as a student in a college, if possible, all homework would be done on campus. In the dormitory, I would prefer to do other things such as take a rest or did my SOW (stand for student on work. Since the students are scholarship students, they are required to work for certain hours). But constructivism forced me to get into the classroom not as an empty bottle. Instead I needed to construct my own understanding thus want it or not, we needed to read. It challenged me but at the same time it was difficult for me because I had other lists to do"

\section{DISCUSSION}

The data analysis that resulted categories on research question 1, 3, 4 and 5 seem to display consistency. The students emphasized on making connection as the definition of constructivist based learning $(n=8)$. Making connection was clearly 
expressed in teacher's probing questions provided by the lecturer and used in activities such as reading before class, class discussions, Facebook online discussion and Ted Talks. The typical probing questions provided in the activity reading before class are the questions to check to what extend the assumptions of each theory true and workable on their personal life at large and specifically on their personal learning experiences (as attached on appendix A).

The questions were intentionally personalized by using the word "you”, "your", "tell your story" in order to encourage each one of the student using their own prior experiences or schema on understanding the information as proposed by Lefrancois (1999) that constructivist teaching approach should stress building relationship the information with what they already know. Moreover Lefrancois proposed strategies that involve interpreting, analyzing and evaluating in the process of building relationship (Lefrancois, 1999). The process of constructing occurred as the students interpreted the texts they read into their personal experiences when answering questions given. Having provided teaching strategies that gradually develop their schema, it makes sense the students responded that making connection which has close meaning with what they mean with think critically become their challenges as well as their difficulty in the constructivist classroom.

Second, the data on research question 3 show that activities experienced by the students helped them in the process of developing their schema as Lefrancois described that developing schema is one of strategies to practice and deepening new knowledge (Lefrancois, 1999). The data might indicate the students' understanding about the theory of constructivist learning was much more gained from what they had experienced in the classroom than listening to groups' presenting this topic. This echoes to Phillips's recommendation of teaching in constructivist classroom that is to give model from the more knowledgeable other in the learning process (Phillips, 2009).

Third, the indication that the students' understanding about constructivist based learning was much more from what they had experienced in the classroom can be seen from one of the interview data about the way Ted Talk facilitated her constructing meaning. She mentioned about guidance from the lecturer, asking for clarification which Santrock says as scaffolding which is one social constructivist approaches to teaching that provide support when needed but it is gradually removed when the students almost complete the tasks given (Santrock, 2009). The term scaffolding was introduced by one of the groups as they presented about social constructivist theory. This term was as well discussed in the classroom. However, the interviewed student did not use that term. Instead she used the word guidance and clarification. Only one student of 21 students used the theoretical terms such as assimilation, adaptation, disequilibrium in his responses both on the survey instrument and in the interview. 


\section{CONCLUSION}

Constructivism learning theory considers the students to construct their own understanding. Thus construction can involve making new connection of the current and previous learning. Giving sets of information and asking the students to copy the information on their note is not implication of what this theory says about learning. The study revealed the students defined constructivism based learning as making connection which is the largest group of definition $(n=9)$ was informed by what they experienced in the Teaching and Learning classroom. Classroom activities which were embedded with assessment required the students to make connection between the theory they learnt and their previous learning such as; writing summary, posting questions, reading others' summary, answering others' questions and creating ted-talks.

Moreover, the students were able to identify the examples of constructivism based learning they experienced in the class as intended of the second research question of this study. This may indicate that they understand the implications of this theory because they acted the theory concretely through the learning activities. The students' response toward the forth and fifth research questions about their challenge and difficulty when learning informed what kind of leaning activities the students had during their school years. 


\section{REFERENCES}

Biesta, G. 2005. "Against Learning: Reclaiming A Language for Education in An Age of Learning,” Nordic Educational Research., 25(1):pp.54-66.

Brummelan. V. 2009. Walking with God in the classroom. Jakarta: Universitas Pelita Harapan.

Eggen. P \& Kauchack. D. 2007. Educational Psychology: Windows on Classrooms Pearson Education. New Jersey,USA

Government's rules document. 2016 number 22. Standard Process on Indonesian's National Curriculum 2013.

Gredler. M. E. 2001. Learning and Instruction: Theory into Practice. New Jersey: Merrill Prentice Hall. 4th ed. USA.

Jonassen. D. H. 2006. “A Constructivist's Perspective on Functional Contextualism Educational Technology,” Research and Development”.,54(1): pp. 43-47.

Kirschner. P.A, Sweller. J, and Clark. R. E. 2006. Why Minimal Guidance During Instruction Does Not Work: An Analysis of the Failure of Constructivist, Discovery, Problem-Based, Experiential, and Inquiry-Based Teaching. http://dx.doi.org/10.1207/s15326985ep4102_1

Lefrancois. G R. 1999. Psychology for Teaching. Stamford: Wadsworth/Thomson Learning. 10th ed. USA

O’Donnell. A. M, Reeve. J, and Smith. J. K. 2007. Educational Psychology: Reflection for Action. Hoboken: Jay O’Callaghan. New Jersey.

Phillips. D.C. \& Soltis J. F. 2009. Perspective on Learning. Columbia University: Teachers College Press. New York.

Santrock. J. W. 2009. Educational Psychology. New York: McGraw-Hill. 4th ed. USA.

Smith. F. 1998. The Book of Learning and Forgetting.Teachers College Press. New York. 